\title{
Static Admittance
}

National Cancer Institute

\section{Source}

National Cancer Institute. Static Admittance. NCI Thesaurus. Code C60917.

The maximum compliance (mobility) of the middle ear system (i.e., the greatest amount of acoustic energy absorbed by the middle ear system (the vertical peak of the tympanogram tracing). 